\title{
Cancer and beyond: the formation of BACUP
}

\author{
VICKY CLEMENT-JONES
}

\section{Introduction}

This article describes my experiences as a doctor with cancer and how this has led to the formation of a new cancer organisation in Britain, BACUP (British Association of Cancer United Patientsand their families and friends). BACUP is being launched on 31 October 1985. It will provide a national cancer information service for patients, their relatives, doctors, and other health professionals. The enclosure with this issue of the $B M \mathcal{F}$ details its services, background, and aims.

\section{Diagnosis}

In September 1982 I was found to have advanced ovarian cancer. I was aged 32, a busy research fellow working on the enkephalins and endorphins, and senior registrar in the department of endocrinology at St Bartholomew's Hospital in London. I had always enjoyed good health until the year before the diagnosis, when I had had rheumatic fever, followed eight months later by a perforated appendix and pelvic abscess. Later when I had further abdominal pain and diarrhoea a recurrent pelvic abscess was suspected and I underwent an exploratory laparotomy. Still sleepy from the anaesthetic I asked the houseman what they had found and was faced with the reply, "It was not an abscess; the professor will come to see you tomorrow." I feared the worst, and the next day my fears were confirmed. A stage III ovarian adenocarcinoma had been discovered, which was inoperable, despite a specialist gynaecological oncologist surgeon being called to the theatre.

Four days of devastation, fear, anger, and the question "why me?"

BACUP (British Association of Cancer United Patients and their Family and Friends), London EC1M 6AA

VICKY CLEMENT-JONES, MB, MRCP, chairman and honorary director

Correspondence to: Dr Clement-Jones, BACUP, 121-3 Charterhouse Street, London ECIM 6AA. followed. The sadness and numbness of the diagnosis shattered my world and the horizons and expectations that my husband and I had known. We both thought that I was unlikely to be alive at Christmas and sadly and reluctantly came to some acceptance of the diagnosis. I was left with the thought that no treatment was available. I, with my family and close friends, endeavoured to make the most of the time we had left together.

Having faced this hopeless situation I found that the visit by my medical oncologist brought hope beyond our wildest dreams. He told us that the chance of eradication of the disease was only $20 \%$. $\mathrm{He}$ carefully explained that treatment would comprise an arduous course of six months' cytotoxic chemotherapy combined with surgery. Despite the fact that the treatment offered would be difficult to endure, and that the chances of success were not very great, this offer gave us something to strive for. At this interview we established a relationship of communication and trust on which we could build. This undoubtedly eased the burden of the problems that lay ahead.

With this information I was able to weigh up the costs and benefits of treatment. On the one hand, I would be committing myself to a prolonged course of debilitating and potentially dangerous treatment. On the other hand, I might gain my life. I accepted the treatment.

In these few days I crossed the divide from doctor to patient. I realised that I had previously had no concept of how it felt to be a patient with cancer or of the emotions and problems patients and their families faced. For the first time in my life I had to face my own mortality. Despite having looked after ill and dying patients, I felt very poorly equipped to deal with my emotions and the uncertainties that lay ahead.

\section{Treatment}

I was initially treated with three monthly courses of cisplatin, doxorubicin, and cyclophosphamide. I experienced the severe nausea and vomiting associated with cisplatin and total loss of hair. Mentally I had prepared myself for the likelihood of losing my hair and having to wear a wig; but the physical reality of the hair falling 
out posed emotional and practical problems which I had not anticipated. For two weeks I was in tears every morning, plucking the clumps of hair from all over the bedclothes; and while I was trying to lead a normal life I had the embarrassing experience of hair falling into my minestrone. Intellectually I understood what was happening, but emotionally it reinforced my feelings that I was losing a part of myself.

I eventually came up with a simple solution to deal with this: wearing a hairnet in bed at night and under a wig if I went out during this time of heavy hair loss. This considerably minimised the trauma. I realised that this was a practical solution to a problem of which other patients might not be aware. I also wondered whether doctors and nurses looking after cancer patients had come across this problem, let alone the solution. I subsequently found that most had not. In the months of treatment that followed other examples of how I and other patients learnt to cope with problems both physical or emotional became apparent. I later coped well with complete baldness: after some initial shyness I abandoned my wig for a selection of attractive hats which I found more comfortable and made me feel more at ease.

The initial chemotherapy shrunk the tumour sufficiently to allow surgery, and in November 1983 oophorectomy, hysterectomy, and omentectomy were performed. The joy that the tumour was responding to chemotherapy was mingled with sadness at the loss of my fertility and the fears of the hurdles ahead. I learnt for the first time of the importance of the support that fellow patients with cancer could give me; of the camaraderie and the value of the shared knowledge of the practical aspects of coping. My initial chemotherapy had all been given in a side room on a surgical ward. Being a doctor I was given the supposed advantage of the privacy of my own room; thus I had not met other patients with cancer. When I went for surgery to the gynaecological ward I finally met a fellow young patient with ovarian cancer. We shared our experiences of chemotherapy, anticipatory vomiting, the trauma of repeated venepuncture with ever vanishing veins, the loss of childbearing, and the onset of menopausal hot flushes, and in this way we supported each other through these difficult times. Through this experience I realised that other patients could give me something unique which I could not obtain from my doctors or nurses, however caring.

There then followed three further monthly cycles of the same chemotherapy complicated by two episodes of prolonged bone marrow suppression and the development of a peripheral neuropathy. I felt very anxious about the increasing numbness and paraesthesia in my hands and feet and the difficulty I noticed in writing, holding cups, walking, and driving a car. The treatments and complications had resulted in considerable debility.

On completion of the chemotherapy cycles in April 1983 I went in trepidation to the operating theatre for my third laparotomy. Unbelievably, the laparotomy revealed no macroscopic evidence of disease; multiple biopsy specimens, however, showed small areas of adenocarcinoma in a few sites. Now we entered uncharted territory and faced the difficult decision whether or not to have further debilitating and again potentially dangerous treatment to eradicate any residual microscopic disease. Success appeared to be within our grasp and we opted for further treatment. In June 1983 I received a single cycle of very high dose cyclophosphamide which required hospital admission for one month and intensive support with antibiotics and platelet and blood transfusions.

\section{Return to work}

After 14 months of intensive treatment and ill health I returned to my full time work in October 1983. Rather than feeling elated, to my surprise I found myself feeling profoundly depressed. The transition from being "a patient and ill" to "well and back at work" brought its own problems. I had struggled to stay alive for 14 months and all my energies had been channelled into treatment and getting better. It was difficult to refocus my life on living and planning a future again. It was not easy to reinvest in the future when it still seemed so uncertain and recent treatment so near. I was also still debilitated from the illness and its treatment and was struggling with the rigours and responsibilities of normal life. The $\underline{\underline{T}}$ depression seemed all the more bizarre to those close to me, who thought I should be overjoyed that treatment was completed. At a $\cong$ time when friends and relatives felt they could for the first time relax their care and attention I felt that I needed their support almost $\stackrel{\varrho}{\bar{F}}$ more than ever.

About this time I began to attend two cancer patient support $\mathbb{\Phi}^{D}$ groups at St Bartholomew's and Hackney hospitals. These groups comprised informal monthly meetings among patients, relatives $\varrho$ and friends, and doctors and nurses to discuss matters of common $\ddot{\vec{\prime}}$ interest. Discovering that other patients had experienced the same feelings of "let down" and depression when they felt theiro "umbilical cord" to hospital had been severed at the end of intensive treatment provided me with some comfort. Attending the groups as $\frac{\bar{c}}{\frac{1}{\sigma}}$ well as reading articles written by patients who had been through $\stackrel{\Phi}{\varnothing}$ similar experiences also helped me ${ }^{1-3} \mathrm{I}$ learnt that I was not alone in feeling "social isolation" during my illness, that some friends on hearing the diagnosis of cancer never contacted me or my husband? again.

I eventually came out of my depression and it was a further eight $\stackrel{\omega}{\omega}$ months before I began to regain my old energy. My colleagues at $\frac{\sigma}{3}$ work were very supportive through these difficult times and helped me to reintegrate into my job. I settled back into my clinical and 0 research career but felt a great need to change its direction to put to use the experience that I had gained. I considered retraining as a $O$ medical oncologist but knew that there would be few senior posts in.this competitive specialty, and, furthermore, I had to recognise that my recent ill health was a drawback. I became committed to the idea of retraining as a general practitioner which would allow me at some $\frac{\rho}{2}$ time in the future to work part time in cancer care. As things have $\vec{N}$ turned out, BACUP has fulfilled these needs and more.

\section{Recurrence}

Initially any twinge or mild abdominal symptoms brought the anxiety of a possible recurrence with it; but, as the months slipped by and the regular follow up visits to my oncologist became more routine, I dared to lift my horizons to five years and perhaps beyond. I was well, happy to be alive, and leading a normal life except for a mild peripheral neuropathy which limited walking far or standing $\frac{\mathcal{Q}}{\mathcal{Q}}$ for long and I had to drive an automatic car.

In October 1984 , a year after my return to work, a recurrence $\overline{\overline{0}}$ detected at a routine visit to the clinic shattered my world again. I 3 felt depressed and angry at the unfairness of it all; I felt I had been through enough. I had to come to terms with my shifting horizons, which had to be lowered yet again, and the upheaval of having somehow to start all over. Those fading memories of frequent visits to hospital would become once more the reality.

The news after the laparotomy brought both hope and sadness. I was hopeful of the future with the news that the surgeon had been $\delta$ able to resect all macroscopic recurrent tumour but sad that the 3 surgeon had left me with a permanent sigmoid colostomy. This brought new problems for my husband and me to cope with. In the first few weeks it seemed hard to imagine how I would ever adjust to it. Now ten months after living with a colostomy has become justo part of my normal life and is to me a small price to pay for the possibility of future health. I have subsequently had further 0 chemotherapy and a good response. I have survived the experiences $\omega$ I describe and now remain well with a "window of hope" for the? future.

\section{Lessons learnt from my illness}

I have described my medical history in some detail to give the $\frac{\mathscr{\Phi}}{\overparen{D}}$ reader an idea of some of the medical problems that $I$ and other $\unrhd$ patients in similar situations have faced. Looking back on those? months and the catalogue of treatments and complications one 8 might think that it was a time only of sadness and suffering. Yes, IO suffered pain and discomfort, yet I learnt something about myself during my illness. I learnt about how precious life was and how I 
wanted to live my life. I learnt about my relationships with my friends and family and how important they were to me, and how the illness had brought us closer together. I was surprised to find that life could be enriched by such traumatic illness. Somehow the experience of my personal struggle with the illness had sharpened my focus on life. I reorganised my priorities and had a new zest for life, living each day as it came. Each day was a bonus and this knowledge was a gift that could not be taken away from me. These perceptions are not unique to me and are the "secondary gains of illness" which other patients with cancer have described before me. ${ }^{12}$

My friends (including my medical colleagues) were surprised how I could get quite good "quality of life" even during those months of treatment. "Quality of life" is a concept we all understand but is difficult to define. ${ }^{4}$ It has been described as "the extent to which a person's hopes and ambitions are matched and fulfilled by experience." It has been suggested that you may be able to improve quality of life by "narrowing the gap between a person's hopes and expectations and what actually happens." By changing my expectations during treatment I was able to achieve quite a satisfactory quality of life even with considerable debility. I derived the greatest joy from the simplest of pleasures and achievements such as being able to walk round my garden, or going out to dinner with friends for the first time after chemotherapy. Rather than focusing on the frustrations of not being able to do things, I concentrated on the things I could achieve and derived satisfaction and pleasure from this.

Looking back on the treatments and the problems I have faced I have thought about the systems of support that have kept me going. Throughout my illness I have felt that I was in a rather privileged position and had many advantages compared with my non-medical fellow patients. I was a doctor who had the advantage of knowing the right questions to ask to seek information about my illness and its treatment; armed with this information I was in a good position to weigh up the pros and cons of a particular treatment. For me the hospital was not a strange environment; I was treated where I had worked and I felt at ease; I also felt fortunate that I was looked after in a specialist cancer unit where the staff were aware of the emotional and psychological problems faced by cancer patients and their families. I had an open and trusting relationship with my medical oncologist. Through this relationship I learnt that communication was a key to overcome the problems I had to cope with. ${ }^{+}$ Together we faced the complications of the illness and treatment and the joys of our successes. I realised too that the continued love and support provided by my family and close friends was an essential part of my mechanisms of coping with my illness and its treatment.

I believe that the access I had to medical information about the illness and its treatment and the climate of open communication between myself, my family and friends and my doctors, contributed significantly to my quality of life. Through this information provided by my medical oncologist I was able to understand how the disease and treatment might affect me and to anticipate problems and to plan my life accordingly. With this knowledge and through open communication, I was able to share my illness and problems with my close family and friends. This considerably lightened my burden. For my family and friends, too, the illness became less frightening and with me they were able to work towards improving my quality of life.

I realise now that I may have missed an opportunity of making a substantial improvement in the quality of life of the patients with cancer I had looked after as a junior doctor when they were denied knowledge of the diagnosis and the opportunity for open communication with the family and the medical team.

\section{The need for information}

During my illness I was struck by the great need for information that both patients and their families had, despite the efforts made by the medical and nursing staff. For the average patient and family members the diagnosis of cancer brought a bewildering and frightening world. Information was being provided on visits to the general practitioner's surgery or hospital, at often emotionally charged interviews, when it is difficult to absorb or understand the information given. As a doctor I had and could obtain all the medical information I needed. I still felt, however, that there was a gap in information available about the practical aspects of coping which I had to learn by hard trial and error over the years.

As I became more experienced other patients would come to see me on the ward as they felt I was "on the inside," being both a patient and a doctor. They wanted to understand more about their illness and its treatment-although they had received explanations. For example, they often needed explanations again and again to why chemotherapy was proposed and how it worked. I knew from my own experience that even as a doctor I needed to hear information repeatedly before it would sink in. I found that patients and family members wanted to be involved and that patients wanted to do something to help themselves during treatment. Perhaps by being involved they could regain some control over the situation. ${ }^{13}$

I realised that there were two levels of information that the patients were seeking from me: one on a medical professional level and the other drawing on my experience as a "veteran" patient who had knowledge that only someone who has "been there" has. It became clear that the doctors and nurses had provided me only with the first level of information. The personal experience was unique to patients and their families and friends. This vast wealth of experience I felt was not being tapped effectively. In support groups I attended I found that an exchange of information did occur but discussions were usually general. I found many patients needed more specific information. Recent experience with cancer "phonelines" in Britain has clearly shown that patients and members of the general public are eager for specific information about cancer. . $^{-8}$

The concept of BACUP has evolved from the need to combine the two levels of information I describe-medical and experientialand to make them generally available to cancer patients and their families. I also felt that many doctors would find such a resource invaluable.

BACUP has been formed as a partnership between experienced patients with cancer and their families and friends and the health professionals working together. It will provide a national cancer information service staffed by oncology trained nurses drawing on the knowledge of medical specialist advisers and experienced patients. A research project will evaluate the service provided and assess the possible benefits to the community. BACUP aims at improving the quality of life for patients with cancer by providing information and improving communications.

BACUP will provide a forum for the exchange of information and the pooling of practical knowledge about living with cancer and its treatment. This concept in health care is not new in Britain; as an endocrinologist I was aware of the work of the British Diabetic Association, which celebrated its fiftieth anniversary last year. Diabetics could turn to the BDA for advice and information provided through booklets and audiovisual materials; the BDA acted as an exchange of practical and medical information to help diabetics cope with their illness and its treatment through its newspaper. In similar ways BACUP aims at filling the information gap for patients with cancer and their families.

\section{References}

1 Fiore N. Fighting cancer-one patient's perspective. N Engl f Med 1979;300:284-9.

2 Cohn KH. Chemotherapy from an insider's perspective. Lancet 1982;i:1006-9.

3 Skinner B. How to participate in your own health. A cancer patient's view. Lancet 1984;ii:971-2.

4 Slevin ML. Quality of life in cancer patients. Clinics in Oncology 1984;2:371-90.

Calman KC. Quality of life in cancer patients-a hypothesis. Fournal of Medical Ethics 1984;10: 124-7.

6 Rayner C. The role of women's magazines. In: Deely TJ, ed. Communication and cancer education. Proceedings of a symposium organised by Tenovus Cancer Information Centre. Cardiff: Tenovus, 1980.

7 Calman KC. Cancer line-an experiment in communication. Health Education foumal 1984;42: 102-3.

8 Eardley A. Medicine and the media. Br Med F 1984;289:1068.

(Accepted 24 September 1985) 